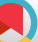

\title{
Nurses' Bedsore-Related Knowledge in Sanandaj Educational Healthcare Centers
}

\author{
Shadiyeh Kanani, ${ }^{1}$ Nasrin Aliramaii,, ${ }^{2,}$ and Ghobad Moradi ${ }^{3}$ \\ ${ }^{1}$ BSc Nursing student, Student Research Committee, Kurdistan University of Medical Sciences, Sanandaj, IR Iran \\ ${ }^{2}$ Science Committee Member of Faculty of Nursing and Midwifery, Kurdistan University of Medical Sciences, Sanandaj, IR Iran \\ ${ }^{3}$ Department of Epidemiology, Kurdistan University of Medical Sciences, Sanandaj, IR Iran \\ "Corresponding author: Nasrin Aliramaii, Science Committee Member of Faculty of Nursing and Midwifery, Kurdistan University of Medical Sciences, Sanandaj, IR Iran. E-mail: \\ n-aliramaei@yahoo.com
}

Received 2017 May 27; Revised 2017 September 12; Accepted 2017 October 02.

\begin{abstract}
Background and Purpose: A bed sore is a major problem in hospitalized patients, which can cost a lot for the patients, families, hospitals, health care institutions, and the community as a whole. On the other hand, one of the duties of the nursing staff is the care of the patient's skin to prevent the formation of an ulcer. In addition, they are also responsible for providing the necessary measures to prevent the onset of pressure ulcers in the hospital. This critical role of nurses itself requires improving their knowledge regarding compression ulcers. The aim of this study was to determine the knowledge level of nurses in Sanandaj sanitary care centers, which was done in 2014 for bedsores.

Methods: This cross-sectional study was conducted in 2014 on 390 nurses from Sanandaj health centers that were selected by the census. Data were collected using the Piperfahr questionnaire. Data analysis was done using the SPSS software and necessary tests. Results: The rate of correct answers related to the onset of bedsore with the highest frequency being 77.7\% in the range of "good", the bedsore evaluation with the frequency of $48.7 \%$ in the range of "average, and that of the bedsore-related knowledge with the highest correct answers of $94.6 \%$ in the range of "good". There was a significant relationship $(\mathrm{P}<0.05)$ between these 2 hospitals in both scopes of evaluation and bedsore onset, however, no relationship was observed between nurses' age, gender, level of education, as well as their bedsore-related knowledge $(\mathrm{P}>0.05)$.

Conclusions: The results showed that, with the highest frequency of correct answers (86.2\%), the nursing knowledge is in an average level. Therefore, their level of knowledge can be promoted by additional relevant learning. Furthermore, the level of knowledge can have a positive effect on the performance.
\end{abstract}

Keywords: Bedsore, Nursing Knowledge, Pressure Ulcer, Educational Healthcare

\section{Background}

A bedsore or pressure ulcer is a damage caused by prolonged pressure on the tissue, which ultimately leads to the destruction of the underlying tissues (1). This common, chronic, but preventable damage, occurs in populations with a high level of risk (2). These wounds gradually recover as a result of excessive pressure on vascular capillary systems. However, osteomyelitis deficiency causes local systemic infections $(3,4)$. Predominant areas of pressure ulcers are areas such as the posterior region of the head, sacrum, shoulders, buttocks, elbow spine, heel, and polyx (5). Ulcer pressure treatment depends on ulcer infection, degree of weakness, simultaneous infection, and associated complications (6). First and 2nd degree ulcers are generally managed by conservative approaches such as elimination of ulcer-creating pressure, ulcer cares, and improvement of patient's nutritional status (6). Third and 4 th degree ulcers are treated by surgical interventions such as debridement of necrotic, infectious tissues, bone cutting, and reconstruction of soft tissue defect, which is situated on bony prominences (7).

Regarding the clinical setting, the incidence of pressure ulcers widely varies from $0.4 \%$ to $66 \%$, with a higher prevalence in patients with a neck and leg bone fracture as well as those with Quadriplegia (8). As a global problem, bedsore occurs in 5\% - 10\% of the in-patients (9). In Iran, the rate of pressure ulcers, in general and in special wards, were reported as 5\%, and $10.1 \%-21 \%$, respectively (10). Also, the incidence of bedsores in Lindgren et al. was reported as $14.3 \%$ and $8.6 \%$ for surgery and internal wards, respectively (11). The mortality rate in patients with a bedsore is 2 - 6 times more than other patients (9). According to the 
conducted studies, the incidence of a bedsore can increase the hospitalization duration by $4.31 \%$ of one day (12).

Nurses, as a medical staff in the field of health care, as well as their knowledge, have a key role in predicting, preventing, treating, and also the prevalence of bed sores in patients with health care systems (13). Since any shortage of knowledge will lead to wrong perception of healthcare measures for bedsores, high-quality and proper healthcare measures require adequate knowledge as well as accurate perception (14). Therefore, it is necessary to increase the bedsore-related nursing knowledge to improve the quality of cares taken by nurses (15). Moore et al. in Ireland, showed that although few nurses were educated adequately regarding bedsores, there was a positive attitude towards bedsores and its preventive measures (16).

Since the occurrence of compression wounds and the increase in mortality rates in society can impair the quality of life of the individual and their family as well as impose social and economic consequences on society (17), the level of knowledge and knowledge of nurses can have a significant impact on their performance (14).

\section{Objectives}

Therefore, according to the above, the present study was conducted in Besat and Tohid educational healthcare centers of Sanandaj in 2014 to determine the level of bedsore-related nursing knowledge. The results may be used in educational planning to improve the nurses' scientific and practical level.

\section{Methods}

This cross-sectional study was conducted in 2014 on 390 nurses that were selected by the census and worked in the health centers of Tohid and Besat, in the city of Sanandaj. In this study, data collection tools included the Pyro's questionnaire for assessing knowledge with the highest amount of credit in the wound under pressure. This questionnaire was designed based on the North American guide to predicting and preventing pressure ulcers, which was used in many countries for nurses' knowledge assessment (18). It is noteworthy that Rafi et al. used this questionnaire in a study to assess the knowledge of nurses and its stability, as well as to make the necessary changes by the professors after translation. The questionnaire was subjected to an internal correlation with a separate calculation. The Cronbach's alpha coefficient was performed for each question and the overall result was 88 (19). The questionnaire included 9 demographic questions and 41 true / false, which the latter was classified into 3 categories. A total of 6 of the nursing knowledge questions were about the onset of pressure ulcers, 2 about the specifications of pressure ulcers, and 33 about preventive measures of pressure ulcers. Before filling the questionnaire, the necessary explanation about the study and its goals were given to the nurses by the researcher. In case of stating the consent to participate in the study, they were given a questionnaire and were asked to answer the questions carefully on their free time. They were also given the choice to leave the study whenever they wanted. The participants were assured that the obtained results would be confidential and would only be used for defined purposes of the study.

Statistical Analysis: After completing and collecting, the obtained data were entered into SPSS22 software for statistical analysis and the descriptive statistics and Chisquare test were analyzed. The nursing knowledge score would be obtained by accumulation of total correct answers. This means that the correct answers above $80 \%$ were considered as good, $41 \%$ to $79 \%$ were average, and below $40 \%$ had a poor level of nursing knowledge.

\subsection{Ethical Consideration}

This study was conducted by the financial support of deputy of research and technology of Kurdistan Medical Sciences University, under the registration number of 93/129.

\section{Results}

A total of 390 nurses from the staff of Sanandaj Besat and Tohid hospitals completed the questionnaire, 200 of them from Tohid and 190 from Besat hospitals. The participants consisted of $76.66 \%$ female and $23.34 \%$ male nurses. The age range of participants with the highest frequency was 26 - 30 years and the average work experience was 5 years. Out of the 390 participants, 25 nurses had a M.S degrees, the rest had a B.S. and A.S. Most participants (79.74\%) were working in circular shifts. Of the participants, $38 \%$ stated their job satisfaction as average. The correct answers to the questions of bedsore onset circumstances, evaluation, and prevention were rated as good (the highest frequency of correct answer as 77.7\%), average (the highest frequency of correct answers as $48.7 \%$ ), and average (the highest frequency of correct answers as 94.6), respectively. An average nursing knowledge was determined with the highest frequency of correct answer as $86.2 \%$ (Tables 1 and 2).

According to Table 3, there is a significant difference between the nurses' correct answers related to the bedsore onset circumstances $(\mathrm{P}<0.05)$. Considering the high risk of a bedsore in special wards, the nurses' correct answer of $82 \%$ and $59 \%$ were determined for ICU and CCU wards, respectively. 
Table 1. Frequency Distribution of Nurses' Correct Answers Related to Bedsores in 3 Scopes of Onset, Evaluation, and Prevention from Bedsore ${ }^{\mathrm{a}}$

\begin{tabular}{lccc}
\hline & \multicolumn{3}{c}{ Scope of Knowledge } \\
\cline { 2 - 4 } $\begin{array}{l}\text { Level of } \\
\text { Knowledge }\end{array}$ & $\begin{array}{c}\text { Bedsore Onset } \\
\text { Circumstances }\end{array}$ & $\begin{array}{c}\text { Bedsore } \\
\text { Evaluation }\end{array}$ & $\begin{array}{c}\text { Bedsore } \\
\text { Prevention }\end{array}$ \\
\hline Poor & $2(0.5)$ & $18(4.6)$ & $2(0.5)$ \\
Average & $85(21.8)$ & $190(48.7)$ & $369(94.6)$ \\
Good & $303(77.7)$ & $182(46.7)$ & $19(4.9)$ \\
\hline Total & $390(100)$ & $390(100)$ & $390(100)$ \\
\hline a & & & \\
\hline
\end{tabular}

${ }^{\mathrm{a}}$ Values are expressed as No. (\%).

Table 2. Frequency Distribution of Nurses' Correct Answers Related to General Bedsore $^{\mathrm{a}}$

\begin{tabular}{lc}
\hline Level of Knowledge & Scope of Bedsore Knowledge \\
\hline Poor & $53(13.6)$ \\
\hline Average & $336(86.2)$ \\
\hline Good & $1(0.3)$ \\
\hline Total & $390(100)$ \\
\hline
\end{tabular}

${ }^{\mathrm{a}}$ Values are expressed as No. (\%).

According to the results of Table 4, there is a significant difference between nurses' correct answers of bedsore prevention knowledge and the duration of job experience $(P$ $>0.05$ ). Nurses who had a job experience of 20 - 30 years showed a higher level of bedsore prevention knowledge.

\section{Discussion}

The results of the present study are as follows: the nursing staff of Tohid hospital got the highest level of correct answers in both scopes. Since giving services to long-term in-patients, Tohid hospital requires nurses with a high level of theoretical and practical knowledge for inpatients' healthcare measures, leading to the increased nursing knowledge. It seems that long-term nursing and study of patients will affect the improvement of nursing knowledge. This hypothesis was proved by Chin Kea and Rosy (2010). According to them, nursing knowledge of bedsore incidence and prevalence as well as bedsore prediction, prevention, and treatment play key roles in healthcare systems. According to the gender, there is no significant difference in knowledge of bedsore onset circumstances, evaluation, prevention, and general knowledge. It could be stated that the same result has been acquired in most scientific studies, e.g., Mohammadi et al. (2009) in Semnan (Iran), Azar Souzani et al. (2012). According to the latter, the mean increase of awareness score, after the education of bedsore healthcare measures, in males and females were 3.78 - 4.22 and 3.86 - 3.92, respectively, showing no relationship between gender and mean increase of scores. According to the level of education, there is a significant difference in the knowledge of bedsore onset circumstances, evaluation, and prevention. Education is considered as a major factor in nursing knowledge for pressure ulcer care. In most studies, including the present one, the relationship of nursing quality and knowledge was proven. The results of the present study are consistent with Beeckman et al. (2010). Although many nurses had a suitable level of basic information regarding risky factors and body parts, a considerable number of them did not have an adequate knowledge of bedsore-creating materials, resulting in a negative effect on performance. Therefore, in order to manage the injuries of an ulcer pressure, it seems to be necessary to improve the nursing knowledge and experience. According to job experience, there was a significant difference in the knowledge of bedsore prediction. Nurses who had a job experience of 20 - 30 years had a higher level of bedsore prevention knowledge. Findings of the present study are consistent with Hormatossadat Emamzadeh Ghasemi (2004). According to them, the quality of nursing cares and patient education in the experiment group increased significantly. Furthermore, there was a significant difference between experiment and control groups in the quality of nursing cares and patient education. According to job shift-time, marital status, and job satisfaction, there was no significant difference in nurses' correct answers of knowledge of bedsore onset circumstances, evaluation, prevention, and general knowledge. Findings of the present study are consistent with Zohreh Vanaki (2003), titled as "The effect of applying executive pattern of in-service nursing education on the quality of nursing cares in surgery ward". According to Vanaki, regarding variables such as age, marital status, level of education, and job experience in surgery ward, nurses were in the same situation in experiment and control groups.

According to age, there was a significant difference in the nurses' correct answers of knowledge of bedsore prevention. Nurses in the age range of 26 - 30 years gave the highest correct answers of the knowledge of bedsore prevention. Azar Souzani et al. reported that most of research unit were female (74\%) and had a M.S of nursing (77\%). After education, nurses' scores increased significantly in the scopes of prevention and treatment. The education had no effect on nurses above 40 years and those with a job experience of 10 years; there was no significant difference in the scores observed. Nursing knowledge of the strategic cares of a bedsore was in a level less than average, resulting in inconsistency of the present study with that of a conducted one. According to the present study, nurses with a job expe- 
Table 3. Frequency Distribution of Nurses' Correct Answers Related to the Bedsore, According to the Wards ${ }^{\mathrm{a}}$

\begin{tabular}{|c|c|c|c|c|c|c|c|c|c|c|c|c|}
\hline \multirow{2}{*}{$\begin{array}{l}\text { Scopes of Care } \\
\text { Level of Knowledge in Each Ward }\end{array}$} & \multicolumn{3}{|c|}{ Level of General Knowledge } & \multicolumn{3}{|c|}{ Bedsore Prevention Percentage } & \multicolumn{3}{|c|}{ Bedsore Evaluation Percentage } & \multicolumn{3}{|c|}{ Bedsore Onset Circumstances } \\
\hline & Good & Average & Poor & Good & Average & Poor & Good & Average & Poor & Good & Average & Poor \\
\hline ICU & $22(23.4)$ & $72(76 / 6)$ & $0(0)$ & $3(3 / 2)$ & $91(96 / 8)$ & $0(0)$ & $46(48 / 9)$ & $44(46 / 8)$ & $4(4 / 3)$ & $77(82)$ & $17(18 / 1)$ & $0(0)$ \\
\hline Injection & $0(0)$ & $8(100)$ & $0(0)$ & $0(0)$ & $7(87 / 5)$ & $1(12 / 5)$ & $0(0)$ & $8(100)$ & $0(0)$ & $6(75)$ & $2(25)$ & $0(0)$ \\
\hline Emergency & $3(14.3)$ & $18(85 / 7)$ & $0(0)$ & $1(4 / 8)$ & $20(95 / 2)$ & $o(0)$ & $9(42 / 9)$ & $10(47 / 6)$ & $2(9 / 5)$ & $14(66 / 7)$ & $7(33 / 3)$ & $0(0)$ \\
\hline Orthopedic & $0(0)$ & $11(100)$ & $0(0)$ & $0(0)$ & $11(100)$ & $0(0)$ & $5(45 / 5)$ & $6(54 / 5)$ & $0(0)$ & $8(72 / 7)$ & $3(27 / 3)$ & $0(0)$ \\
\hline Brain surgery & $2(25)$ & $6(75)$ & $0(0)$ & $0(0)$ & $8(100)$ & $0(0)$ & $6(75)$ & $2(25)$ & $0(0)$ & $5(62 / 5)$ & $3(37 / 5)$ & $0(0)$ \\
\hline Dialysis & $0(0)$ & $6(100)$ & $0(0)$ & $0(0)$ & $6(100)$ & $0(0)$ & $2(33 / 3)$ & $4(66 / 7)$ & $0(0)$ & $6(100)$ & $0(0)$ & $0(0)$ \\
\hline Infectious diseases & $o(0)$ & $5(100)$ & $0(0)$ & $0(0)$ & $5(100)$ & $0(0)$ & $1(20)$ & $4(80)$ & $0(0)$ & $3(60)$ & $2(40)$ & $0(0)$ \\
\hline Women' heart & $0(0)$ & $1(100)$ & $0(0)$ & $0(0)$ & $1(100)$ & $0(0)$ & $0(0)$ & $1(100)$ & $0(0)$ & $0(0)$ & $0(0)$ & $1(100)$ \\
\hline Men's heart & $2(22.2)$ & $7(77 / 8)$ & $O(0)$ & $0(0)$ & $9(100)$ & $0(0)$ & $2(22 / 2)$ & $7(77 / 8)$ & $0(0)$ & $8(88 / 9)$ & $1(11 / 1)$ & $0(0)$ \\
\hline Gastroenterology & $2(22.2)$ & $7(77 / 8)$ & $0(0)$ & $1(11 / 1)$ & $8(88 / 9)$ & $0(0)$ & $7(77 / 8)$ & $2(22 / 2)$ & $0(0)$ & $8(88 / 9)$ & $1(11 / 1)$ & $0(0)$ \\
\hline Neurology & $0(0)$ & $8(100)$ & $0(0)$ & $0(0)$ & $8(100)$ & $0(0)$ & $5(62 / 5)$ & $2(25)$ & $1(12 / 5)$ & $7(87 / 5)$ & $1(12 / 5)$ & $0(0)$ \\
\hline CCU & $3(7.7)$ & $36(92 / 3)$ & $0(0)$ & $1(2 / 6)$ & $38(97 / 4)$ & $0(0)$ & $21(53 / 8)$ & $17(43 / 6)$ & $1(2 / 6)$ & $23(59)$ & $16(41)$ & $0(0)$ \\
\hline Burn & $o(0)$ & $2(100)$ & $0(0)$ & $0(0)$ & $2(100)$ & $0(0)$ & $2(100)$ & $0(0)$ & $0(0)$ & $2(100)$ & $0(0)$ & $0(0)$ \\
\hline Neonatal & $0(0)$ & $4(100)$ & $0(0)$ & $0(0)$ & $4(100)$ & $0(0)$ & $2(50)$ & $2(50)$ & $0(0)$ & $4(100)$ & $0(0)$ & $0(0)$ \\
\hline Chemotherapy & $0(0)$ & $2(100)$ & $0(0)$ & $0(0)$ & $2(100)$ & $0(0)$ & $1(50)$ & $1(50)$ & $0(0)$ & $2(100)$ & $0(0)$ & $0(0)$ \\
\hline Surgery room & $0(0)$ & $1(100)$ & $0(0)$ & $0(0)$ & $1(100)$ & $0(0)$ & $0(0)$ & $1(100)$ & $0(0)$ & $1(100)$ & $0(0)$ & $0(0)$ \\
\hline Clinic & $o(0)$ & $2(100)$ & $\mathrm{o}(0)$ & $o(0)$ & $2(100)$ & $0(0)$ & $2(100)$ & $0(0)$ & $0(0)$ & $2(100)$ & $0(0)$ & $0(0)$ \\
\hline Nicu & $2(14)$ & $37(86)$ & $0(0)$ & $4(9 / 3)$ & $39(90 / 7)$ & $0(0)$ & $20(46 / 5)$ & $21(48 / 8)$ & $2(4 / 7)$ & $34(79 / 1)$ & $8(18 / 6)$ & $1(2 / 3)$ \\
\hline Oicu & $3(17.6)$ & $14(82 / 4)$ & $0(0)$ & $1(5 / 9)$ & $16(94 / 1)$ & $0(0)$ & $9(52 / 9)$ & $8(47 / 1)$ & $0(0)$ & $14(82 / 4)$ & $3(17 / 6)$ & $0(0)$ \\
\hline Men's surgery & $5(41.7)$ & $6(50)$ & $1(8 / 3)$ & $3(25)$ & $8(66 / 7)$ & $1(8 / 3)$ & $6(50)$ & $5(41 / 7)$ & $1(8 / 3)$ & $11(91 / 7)$ & $1(8 / 3)$ & $0(0)$ \\
\hline Women's surgery & $1(5.3)$ & $18(94 / 7)$ & $0(0)$ & $0(0)$ & $19(100)$ & $0(0)$ & $11(57 / 9)$ & $8(42 / 1)$ & $0(0)$ & $14(73 / 7)$ & $5(26 / 3)$ & $0(0)$ \\
\hline Pediatric & $0(0)$ & $10(100)$ & $0(0)$ & $0(0)$ & $10(100)$ & $0(0)$ & $2(20)$ & $6(60)$ & $2(20)$ & $10(100)$ & $0(0)$ & $0(0)$ \\
\hline Men's internal & $o(0)$ & $18(100)$ & $\mathrm{o}(0)$ & $2(11 / 1)$ & $16(88 / 9)$ & $0(0)$ & $8(44 / 4)$ & $8(44 / 4)$ & $2(11 / 1)$ & $8(44 / 4)$ & $10(55 / 6)$ & $0(0)$ \\
\hline Women's internal & $3(13 / 6)$ & $19(86 / 4)$ & $0(0)$ & $3(13 / 6)$ & $19(86 / 4)$ & $0(0)$ & $9(40 / 9)$ & $13(59 / 1)$ & $0(0)$ & $20(90 / 9)$ & $2(9 / 1)$ & $0(0)$ \\
\hline Oncology & $0(0)$ & $8(100)$ & $0(0)$ & $0(0)$ & $8(100)$ & $0(0)$ & $4(50)$ & $2(25)$ & $2(25)$ & $8(100)$ & $0(0)$ & $0(0)$ \\
\hline Lungs & $1(9.1)$ & $10(90 / 9)$ & $0(0)$ & $0(0)$ & $11(100)$ & $0(0)$ & $2(18 / 2)$ & $8(72 / 7)$ & $1(9 / 1)$ & $8(72 / 7)$ & $3(27 / 3)$ & $0(0)$ \\
\hline Chi-square number & & $66 / 298$ & & & $64 / 338$ & & & $58 / 198$ & & & 239/377 & \\
\hline Level of significance & & 0/061 & & & $084 / 0$ & & & $199 / 0$ & & & $000 / 0$ & \\
\hline
\end{tabular}

${ }^{a}$ Values are expressed as No. (\%).

Table 4. Frequency Distribution of Nurses' Correct Answers Related to Thebedsore According to Job Experience ${ }^{\mathrm{a}}$

\begin{tabular}{|c|c|c|c|c|c|c|c|c|c|c|c|c|}
\hline \multirow{2}{*}{$\begin{array}{l}\text { Healthcare Scopes } \\
\text { Level of Knowledge According to the Job Experience, } y\end{array}$} & \multicolumn{3}{|c|}{ Level of General Knowledge } & \multicolumn{3}{|c|}{ Bedsore Prevention Percentage } & \multicolumn{3}{|c|}{ Bedsore Evaluation Percentage } & \multicolumn{3}{|c|}{ Bedsore Onset Circumstances } \\
\hline & Good & Average & Poor & Good & Average & Poor & Good & Average & Poor & Good & Average & Poor \\
\hline $0-5$ & $27(16 / 8)$ & $133(82 / 6)$ & $1(0 / 6)$ & $8(0 / 5)$ & $152(94 / 45)$ & $1(0 / 6)$ & $66(41)$ & $85(52 / 8)$ & $10(6 / 2)$ & $12(78 / 9)$ & $34(21 / 1)$ & $0(0)$ \\
\hline $6-10$ & $15(11 / 1)$ & $120(88 / 9)$ & $0(0)$ & $9(6 / 7)$ & $126(93 / 3)$ & $0(0)$ & $63(46 / 7)$ & $65(48 / 1)$ & $7(5 / 2)$ & $103(76 / 3)$ & $30(22 / 2)$ & $2(1 / 5)$ \\
\hline 11-15 & $7(14 / 6)$ & $41(85 / 4)$ & $0(0)$ & $0(0)$ & $48(100)$ & $0(0)$ & $28(58 / 3)$ & $19(39 / 6)$ & $1(2 / 1)$ & $39(81 / 3)$ & $9(18 / 8)$ & $0(0)$ \\
\hline $16 \cdot 20$ & $2(7 / 1)$ & $26(92 / 9)$ & $0(0)$ & $0(0)$ & $28(100)$ & $0(0)$ & $18(64 / 3)$ & $10(35 / 7)$ & $0(0)$ & $20(71 / 4)$ & $8(28 / 6)$ & $0(0)$ \\
\hline $20-30$ & $2(11 / 1)$ & $16(88 / 9)$ & $0(0)$ & $2(11 / 1)$ & $15(83 / 3)$ & $1(5 / 6)$ & $7(38 / 9)$ & $11(61 / 1)$ & $0(0)$ & $14(77 / 8)$ & $4(22 / 2)$ & $0(0)$ \\
\hline Chi-square number & & 4/72 & & & $16 / 58$ & & & 11/299 & & & $4 / 109$ & \\
\hline Level of significance & & $0 / 787$ & & & $035 / 0$ & & & $185 / 0$ & & & $767 / 0$ & \\
\hline
\end{tabular}

${ }^{\mathrm{a}}$ Values are expressed as No. (\%).

rience of 20 - 30 years had the highest level of knowledge. It may be due to the fact that updated books and pamphlets accessible by nurses play key roles in their experience and knowledge during long years of service. According to the present study, the nursing knowledge is in an average level and it is required to pay attention to this matter.

Predisposing factors of bedsore incidence consist of: paralysis, lack of movement, loss of sensation, circulatory disorders, loss of consciousness, anesthetic and sedative drugs, high humidity, malnutrition, infection, sweat- 
ing, aging, dehydration, edema, and previous ulceration. Proper measures and high-quality cares require adequate knowledge and proper understanding of a bedsore. Therefore, the present study evaluated bedsore-related nursing knowledge in educational healthcare centers and the following results were acquired: The correct answers to the questions of bedsore onset circumstances, evaluation, and prevention were rated as good (the highest frequency of correct answer as $77.7 \%$ ), average (the highest frequency of correct answers as 48.7\%), and average (the highest frequency of correct answers as 94.6\%), respectively. An average nursing knowledge was determined with the highest frequency of the correct answer as $86.2 \%$. Conclusion: Evidently, the nursing knowledge of a bedsore is not in an adequate level, requiring continuous education to improve nurses' level of awareness and resolve the conflicts of nursing knowledge evaluation in relation to bedsore.

Implication for Practice: Since bedsores can impose serious hazards to the patients in case of any carelessness, it is recommended that the nursing staff improve the knowledge of identification and care circumstances of patients with a bedsore as well as improve the practical knowledge in accordance to the theoretical one. The major limitation of this study was to collect data at one period of time and place.

\section{Acknowledgments}

The researchers thank the heads of Besat and Tohid hospitals of Sanandaj and corresponding nursing officers for providing the executive setting for this study.

\section{References}

1. Mehrabani M, Hosseini MA, Karimloo M. Comparison of Honey dressing with Hydrocolloid dressing effects on pressure ulcer healing of ICU hospitalized patients. J Health Promot Manag. 2012;1(3):37-45.

2. Gargano F, Edstrom L, Szymanski K, Schmidt S, Bevivino J, Zienowicz R, et al. Improving Pressure Ulcer Reconstruction: Our Protocol and the COP (Cone of Pressure) Flap. Plast Reconstr Surg Glob Open. 2017;5(3):e1234. doi: 10.1097/GOX.0000000000001234. [PubMed: 28458961].
3. Taylor C, Lillis C, LeMone P. Skin integrity and wound care. Fundamental of Nursing. Philadelphia: Kuwer A \& woltters; 2005.

4. Morton PG, Fontaine D, Hudak CM, Gallo BM. Critical care nursing: a holistic approach. Lippincott Williams \& Wilkins; 2017.

5. Yaghobi M. BedSore. Tehran: Shasosa; 2010.

6. Cushing CA, Phillips LG. Evidence-based medicine: pressure sores. Plast Reconstr Surg. 2013;132(6):1720-32. doi: 10.1097/PRS.0b013e3182a808ba. [PubMed: 24281597].

7. Agrawal K, Chauhan N. Pressure ulcers: Back to the basics. Indian J Plast Surg. 2012;45(2):244-54. doi:10.4103/0970-0358.101287. [PubMed: 23162223].

8. Larson DL, Hudak KA, Waring WP, Orr MR, Simonelic K. Protocol management of late-stage pressure ulcers: a 5-year retrospective study of 101 consecutive patients with 179 ulcers. Plast Reconstr Surg. 2012;129(4):897-904. doi: 10.1097/PRS.0b013e3182442197. [PubMed: 22183500].

9. Nayak D, Srinivasan K, Jagdish S, Rattan R, Chatram VS. Bedsores: "top to bottom" and "bottom to top". Indian J Surg. 2008;70(4):161-8. doi: 10.1007/s12262-008-0046-4. [PubMed: 23133050].

10. Jalali R. The principle of wound cure and care. Tehran: Salemi publication; 2003.

11. Lindgren M, Unosson M, Fredrikson M, Ek AC. Immobility - a major risk factor for development of pressure ulcers among adult hospitalized patients: a prospective study. Scand J Caring Sci. 2004;18(1):57-64. doi: 10.1046/j.0283-9318.2003.00250.x.

12. Simon M, Bergquist-Beringer S, Gajewski B, Dunton N. Pressure ulcer prevention as an indicator of nursing care quality: a comment on Jull and Griffiths (2010). Int J Nurs Stud. 2010;47(9):1194-5. doi: 10.1016/j.ijnurstu.2010.04.008. [PubMed: 20537644].

13. Papanikolaou P, Lyne P, Anthony D. Risk assessment scales for pressure ulcers: a methodological review. Int J Nurs Stud. 2007;44(2):28596. doi: 10.1016/j.ijnurstu.2006.01.015. [PubMed: 17141782].

14. Beeckman D, Vanderwee K, Demarre L, Paquay L, Van Hecke A, Defloor T. Pressure ulcer prevention: development and psychometric validation of a knowledge assessment instrument. Int J Nurs Stud. 2010;47(4):399-410.

15. Shahin ESM, Dassen T, Halfens RJG. Pressure ulcer prevalence in intensive care patients: a cross-sectional study. J Evaluat Clin Pract. 2008;14(4):563-8.

16. Moore Z, Price P. Nurses' attitudes, behaviours and perceived barriers towards pressure ulcer prevention.J Clin Nurs. 2004;13(8):942-51. doi: 10.1111/j.1365-2702.2004.00972.x. [PubMed: 15533100].

17. Miyazaki MY, Caliri MH, dos Santos CB. Knowledge on pressure ulcer prevention among nursing professionals. Rev Lat Am Enfermagem. 2010;18(6):1203-11. [PubMed: 21340287].

18. Pieper B, Mott M. Nurses' knowledge of pressure ulcer prevention, staging, and description. Adv Wound Care. 1995;8(3):34-38, 40 passim. [PubMed: 7795877].

19. Iranmanesh S, Rafiei H, Foroogh Ameri G. Critical care nurses' knowledge about pressure ulcer in southeast of Iran. Int WJ. 2011;8(5):45964. 